$$
\text { LA-SUB--95-192 }
$$

\title{
RESEARCH ON MICROWAVE JOINING OF SiC
}

\section{Final Report of Subcontract 4008E00014-9G}

(FMT Report No. FMT-95-07-10)

Submitted to:

University of California

Los Alamos National Laboratory

ATTN: R. N. Tokay

P.O. Box 990 MS P274

Los Alamos, NM 87545

Submitted by:

FM Technologies, Inc.

10529-B Braddock Road

Fairfax, VA 22032

DSTRIBUTION OF THIS DOCUMENT IS UNLUATED

Dr. Richard Silberglitt, Principal Investigator

July 31, 1995 


\section{DISCLAIMER}

Portions of this document may be illegible in electronic image products. Images are produced from the best available original document. 


\section{DISCLAIMER}

This report was prepared as an account of work sponsored by an agency of the United States Government. Neither the United States Government nor any agency thereof, nor any of their employees, make any warranty, express or implied, or assumes any legal liability or responsibility for the accuracy, completeness, or usefulness of any information, apparatus, product, or process disclosed, or represents that its use would not infringe privately owned rights. Reference herein to any specific commercial product, process, or service by trade name, trademark, manufacturer, or otherwise does not necessarily constitute or imply its endorsement, recommendation, or favoring by the United States Government or any agency thereof. The views and opinions of authors expressed herein do not necessarily state or reflect those of the United States Government or any agency thereof. 


\subsection{INTRODUCTION AND BACKGROUND}

The combination of high thermal conductivity, excellent thermal shock resistance, and good corrosion resistance makes silicon carbide ( $\mathrm{SiC}$ ) an excellent material for heat exchangers, radiant burner tubes, and advanced heat engine and pump components. Because it is difficult to sinter to net shape and expensive to machine, joining of $\mathrm{SiC}$ is desirable for fabrication of large or complex components or assemblies. Joining of sintered $\mathrm{SiC}$ (SSiC) using conventional diffusion bonding requires $2000^{\circ} \mathrm{C}$, intimate contact and physical constraints to prevent deformation. ${ }^{1}$ Reaction bonded $\mathrm{SiC}$ (RBSC) is an alternative material which is formed by infiltration of a preshaped preform of carbon and $\mathrm{SiC}$ with molten silicon. RBSC is nearly fully dense, with $5-15 \%$ residual silicon. It is a cheaper and more formable alternative to sintered $\mathrm{SiC}$ with slightly lower strength and service temperature.

Under a previous contract, microwave joining of both sintered and reaction bonded $\mathrm{SiC}$ was accomplished. Sintered $\mathrm{SiC}$ was joined to itself using metallic braze interlayers, and direct joints between RBSC and itself and between $\mathrm{SSiC}$ and $\mathrm{RBSC}$ were demonstrated using microwave heating in single mode and multimode cavities, in some cases in combination with radiant heating. RBSC-RBSC and RBSC-SSiC joints between short tube sections with outer diameter between one and two inches were shown to be leak-tight under simulated heat exchanger and radiant burner tube operating conditions and to have adequate mechanical strength for these applications. ${ }^{2}$ Based upon these previous results, the objectives of this project were as follows:

1. Investigation of the dependence of the mechanical properties of the joined tube sections on joining parameters, in order to identify optimum time-temperature profiles for the microwave joining of silicon carbide; and

2. Development of new microwave joining methods that can be applied to accomplish in situ formation of silicon carbide interlayers and to join larger samples required for industrial applications.

\subsection{SUMMARY OF WORK PERFORMED}

\section{Task 1 - Optimization of time-temperature profile}

The objective of this task was to investigate the effect of joining parameters on the microstructural and mechanical properties of joined specimens. In particular, experiments to examine the effect of joining temperature were performed. Tubes of reaction bonded silicon carbide (RBSC) with a diameter of $3.49 \mathrm{~cm}(1.375 \mathrm{in})$ and a wall thickness of $0.476 \mathrm{~cm}(0.1875$ in) were obtained from Golden Technologies, Inc. (Golden Technologies is the Coors company responsible for advanced ceramics R\&D.) Specimens for joining experiments were prepared by

I D. DeLeeuw, J. Am. Ceram. Soc. 75 (3) (1992) p. 725.

2 R. Silberglitt, I. Ahmad, W. M. Black and J. D. Katz, MRS Bull. XVIII (11) (1993) p. 47. 
cutting sections from these tubes $2.54 \mathrm{~cm}(1 \mathrm{in})$ in length. These tube sections were then polished to 5-10 $\mu \mathrm{m}$ surface finish and each pair to be joined was placed inside a hybrid heating enclosure which was insulated on all sides with alumina blankets and boards. The tube sections were butt-joined with pressure applied by a load transmitted via a tube inserted through a 2.54 $\mathrm{cm}(1 \mathrm{in})$ diameter opening in the top of the insulation. The weight of the load was approximately $10.5 \mathrm{~kg}(23 \mathrm{lb})$, which provided a joining pressure of $0.23 \mathrm{MPa}(32.8 \mathrm{psi})$.

Specimens were joined at four different temperatures: $1420^{\circ} \mathrm{C}, 1465^{\circ} \mathrm{C}, 1515^{\circ} \mathrm{C}$ and $1565^{\circ} \mathrm{C}$. In each case, the joining temperature was achieved in $35-45$ minutes using up to 3.5 $\mathrm{kW}$ of microwave input power, with about 500 Watts of reflected power. The specimens were held at the joining temperature for 30 minutes, with the temperature during this time manually controlled to within $15^{\circ} \mathrm{C}$. Microwave power was reduced to about $2 \mathrm{~kW}$ to maintain the joining temperature. The joined specimens were then sent to Los Alamos National Laboratory for evaluation.

Test bend bars were machined from each specimen and Chevron notches machined into the joint interface, as indicated in Figure 1. Figure 2 shows the fracture toughness determined from 4-point flexure tests of the notched test bend bars. The data labeled "no joint" were derived from test bend bars machined from an as-received specimen of RBSC. The average fracture toughness was determined from measurements on 6-8 specimens and the standard deviation is indicated by the shorter bars in Figure 2. The joining temperatures for each specimen were as follows: specimen $1 \mathrm{~A}$ at $1465^{\circ} \mathrm{C}$; specimen $1 \mathrm{~B}$ at $1515^{\circ} \mathrm{C}$; specimen $2 \mathrm{~A}$ at $1565^{\circ} \mathrm{C}$; specimen $2 \mathrm{~B}$ at $1420^{\circ} \mathrm{C}$.

Figure 2 demonstrates that the optimum joining temperature is likely between $1420^{\circ} \mathrm{C}$ and $1500^{\circ} \mathrm{C}$, and perhaps very close to $1465^{\circ} \mathrm{C}$. Specimens joined near this optimum temperature have fracture toughness greater than the as received material. The standard deviation of the fracture toughness values for the joined specimens was also smaller than that for the as received material, except for specimen $1 \mathrm{~B}$, which had one data point with a fracture toughness value far different from all others. Inspection of the fracture surface of this test bar will be performed to see if its failure was caused by a defect in the material or by the specimen preparation process, rather than by failure of the joint.

\section{Task 2 - In situ formation of SiC joints using reaction bonding}

Under this task the $\mathrm{TE}_{103}$ single mode applicator was modified to allow operation under controlled environments such as $\mathrm{Ar}$ or $\mathrm{N}_{2}$, which is necessary for chemical reactions leading to the formation of $\mathrm{SiC}$ in situ during joining. First, a pressure window purchased from Varian (MA1360) was attached at the entry port of the applicator, which allows a maximum gas pressure of $45 \mathrm{psi}$ and a maximum standing wave ratio of 1.15 . Second, the cavity end, the moving plunger and the two holes for temperature measurement were sealed with O-rings. Third, a pair of ultra-torr fittings were connected to the cut-off tubes on the narrow side of the waveguide. The inner diameter (ID) of the fitting can be varied from $0.635 \mathrm{~cm}(0.25$ in) to $1.905 \mathrm{~cm}(0.75 \mathrm{in})$ by introducing a set of adapters to match the size of the specimens. Gas flows in and out of the 
applicator through two fittings located at the front and back sides of the waveguide, respectively. Using this modified cavity, any nonflammable gas can be used as a protective environment for the specimens. This modified cavity was used in all experiments in which polycarbosilane precursor was decomposed to form $\mathrm{SiC}$ in situ, as described under Task 3 below.

\section{Task 3 - Formation of SiC from chemical precursors}

Under the previous contract, $\mathrm{SiC}$ was produced from polycarbosilane (PCS) precursors using both conventional and microwave heating, but direct comparisons were difficult because the microwave decomposition was performed at $1500^{\circ} \mathrm{C}$, while the conventional heating was performed at $1200^{\circ} \mathrm{C}$, the maximum temperature of an available muffle furnace. During this contract, a research grade graphitic furnace at the U.S. Naval Research Laboratory, which is capable of heating to $2500^{\circ} \mathrm{C}$, was used for the conventional processing. This allowed direct comparison of PCS pyrolysis using microwave and conventional heating, with a pyrolysis temperature in both cases of $1400^{\circ} \mathrm{C}$. The PCS used in these experiments was Dow Corning X9-6348 (manufactured by Nippon Carbon Corporation, Tokyo, Japan), with an average molecular weight of 1400 . The microwave heating was performed in a fused silica crucible inside an alumina insulator, which was placed inside the $\mathrm{TE}_{103}$ single mode rectangular cavity at the maximum electric field position of the empty cavity. The modified cavity described under Task 2 was used, and a gas mixture of $95 \% \mathrm{~N}_{2}$ and $5 \% \mathrm{H}_{2}$ was flushed through prior to heating.

Infrared (IR) spectra of the PCS cured by both conventional and microwave heating showed a strong $\mathrm{SiC}$ absorption band centered at $800 \mathrm{~cm}^{-1}$. However, the microwave heating showed a clear advantage both in heating rate (5 times faster) and in the crystallinity of the final product. Figure 3 is a comparison of heating profiles and Figure 4 is a comparison of X-ray spectra, summarizing these results. Published data show that to achieve the sharpness of the $X$-ray peaks observed for the $P C S$ cured with microwave heating at $1400^{\circ} \mathrm{C}$, conventional heating to $1700^{\circ} \mathrm{C}$ is necessary.

Microwave-induced pyrolysis of the PCS was used to join specimens of Hexoloy ${ }^{\mathrm{TM}}$ sintered $\mathrm{SiC}$ by forming $\mathrm{SiC}$ in situ at the interface. The specimens were rods $0.95 \mathrm{~cm}(0.375 \mathrm{in})$ in diameter and $0.5 \mathrm{~cm}(0.197 \mathrm{in})$ long, which were purchased from the Carborundum Company. The same commercial PCS described above was used. The PCS was dissolved in hexane and applied to the surface of one sintered $\mathrm{SiC}$ rod, which had been polished and etched with HF. This $\mathrm{SiC}$ rod was then held in contact with a second $\mathrm{SiC}$ rod under a pressure of $30 \mathrm{psi}(0.2$ $\mathrm{MPa}$ ), and joined in the single mode $\mathrm{TE}_{103}$ rectangular cavity using the configuration indicated schematically in Figure 5. Joining was accomplished in 30 minutes at a temperature of $1400^{\circ} \mathrm{C}$ using approximately $900 \mathrm{Watts}$ of input power. The joined specimens were sectioned and evaluated via Scanning Electron Microscopy (SEM) at Los Alamos National Laboratory. Figure 6 is a representative SEM demonstrating a smooth and homogeneous $\mathrm{SiC}$ interlayer a few microns in width.

3 G. D. Soraru, F. Babonneau, J. D. Mackenzie, J. Mater. Sci. 25 (1990) p. 3889. 
A detailed evaluation was then performed of the effect of surface preparation on this type of $\mathrm{SiC}$ joint. Accordingly, four sets of specimens were prepared using different surface treatments. All four sets of specimens were cut from as-received rods using a Buehler Low Speed Saw and a high concentration diamond blade. The PCS was again dissolved in hexane and applied to the surface to be joined. For the first set of specimens, the PCS solution was applied directly to the as-cut surface. For the second set, the surfaces to be joined were etched in $40 \%$ hydrofluoric acid before the PCS was applied. The joining surfaces of the other two sets of specimens were ground on a diamond wheel. One set of surfaces was then also etched before PCS application, while the other was not.

The specimens were placed in the modified $\mathrm{TE}_{103}$ single mode cavity applicator under a mixed reducing atmosphere of $95 \%$ nitrogen and 5\% hydrogen. Microwave power was coupled to the specimens using an adjustable iris and plunger and the specimens were heated to $1400-1450^{\circ} \mathrm{C}$ and held in this temperature range for 30 minutes. These specimens either did not join or were weakly bonded. However, investigation of the adherence of $\mathrm{SiC}$ formed from the PCS on the sintered $\mathrm{SiC}$ surface indicated that the ground and etched surface was most favorable for joining. An additional set of specimens was then prepared using grinding and etching of the surface. In addition, a mixture of $\mathrm{SiC}$ powder and PCS was applied to the surface to be joined. This set of specimens was heated using the same conditions as above, resulting in a good joint.

Figures 7 and 8 are Scanning Electron Micrographs (SEMs) of the surface of the specimens which had the PCS applied to the as-cut surface and to the ground and etched surface, respectively. Both surfaces were scratched with a sharp metal point under a load of 820 grams in order to investigate the adherence of the $\mathrm{SiC}$ formed from the decomposition of the PCS. Comparison of the SEMs shows greatly enhanced wetting and spreading of the $\mathrm{SiC}$ formed from the PCS on the ground and etched surface. SEMs (not shown) of surfaces that were either ground or etched also showed improvement over the as-cut surface, but the combination of grinding and etching provided the best wetting and spreading. Figure 9 is a higher magnification of the micrograph shown in Figure 8, which indicates that larger flakes of $\mathrm{SiC}$ were peeled off by the metal point, but good coverage of the scratched area remained, suggesting that the smaller flakes were adherent. Figure 10 is an SEM of a cross-section of the specimen joined using the mixture of SiC and PCS, after grinding and etching of the surfaces to be joined. A continuous joint interlayer approximately $50-60 \mu \mathrm{m}$ in thickness was formed. In addition, a combination of the $\mathrm{SiC}$ introduced at the interlayer and the $\mathrm{SiC}$ formed from the PCS completely filled the pores near the interface of the joined specimens.

\section{Task 4 - Development of new microwave applicators for long specimens}

A new single mode applicator was designed and fabricated, composed of two double mitered H-plane waveguide corners (bends). Figure 11 is a schematic of this applicator. Its advantages over the single mitered bend applicator developed under the previous contract are the increased length of the heating zone and the ease with which the sample can be oriented vertically, to allow external compression. This cavity is excited in the $\mathrm{TE}_{104}$ mode or a higher order $10 \mathrm{n}$ mode, depending upon the length of the adjustable short arm. In order to compare this 
new applicator with a rectangular cavity of the same waveguide size, three different ceramic specimens were heated. The specimens were a sintered silicon carbide rod with diameter $\mathrm{d}=$ $0.95 \mathrm{~cm}$ (0.375 in) and length $\mathrm{l}=7 \mathrm{~cm}$ (2.76 in), a RBSC rod with $\mathrm{d}=1.5 \mathrm{~cm}(0.59 \mathrm{in})$ and $\mathrm{l}=$ $6.5 \mathrm{~cm}$ (2.56 in), and a RBSC tube with outer diameter (OD) of $1.5 \mathrm{~cm}(0.59 \mathrm{in})$, wall thickness of $0.2 \mathrm{~cm}(0.079 \mathrm{in})$ and $1=19 \mathrm{~cm}$ (7.48 in). The rod specimens were placed inside a block of alumina insulation and the long tube passed through the insulation. Temperature was monitored with a two color optical pyrometer through a hole in the insulation. In all three cases, the double mitered bend cavity provided a more rapid heating rate and higher specimen temperatures than could be achieved with the rectangular cavity. The effect was greater for the larger specimens. Figure 12 shows the heating data for the RBSC tube, which was heated to almost $1400^{\circ} \mathrm{C}$ with $1.1 \mathrm{~kW}$ of input power, as compared to less than $1200^{\circ} \mathrm{C}$ in the rectangular cavity with the same input power.

The double mitered bend single mode cavity was used to join two RBSC rods. The rods were $1.9 \mathrm{~cm}(0.75 \mathrm{in})$ and $1.5 \mathrm{~cm}$ (0.59 in) in diameter. The lengths of the rods were $5 \mathrm{~cm}(1.97$ in) and $6 \mathrm{~cm}$ (2.36 in), respectively. The cavity and the orientation of the specimens was as shown in Figure 11. The rods were inserted into a block of alumina insulation and placed along the axis of the cavity, which was oriented vertically to allow pressure to be applied with an external hydraulic press. Two alumina push rods $0.9 \mathrm{~cm}$ in diameter and $7.8 \mathrm{~cm}$ long were used to apply the pressure to the top and bottom specimens. Temperature was again monitored using an optical pyrometer. The specimens were brought to a joining temperature of $1455^{\circ} \mathrm{C}$ in approximately 40 minutes by gradually increasing the input microwave power to a maximum value of 1550 Watts. The input power was then held at this value to maintain the joining temperature for 12 minutes. The reflected power during this time was 50 Watts. The joined specimens were sent to Los Alamos National Laboratory for evaluation. Unfortunately, these specimens were destroyed because of an error in machining, so that it was not possible to measure the mechanical strength of the joint.

\subsection{SUMMARY AND CONCLUSIONS}

The principal results of this project were the identification of the optimum joining temperature range for reaction bonded silicon carbide of $1420-1500^{\circ} \mathrm{C}$, the demonstration that specimens joined within this range of temperatures have fracture toughness greater than the as-received material, and the demonstration of the ability to use $\mathrm{SiC}$ formed in situ from the decomposition of polycarbosilane as a joining aid for sintered silicon carbide. In the latter case, the interlayer material was also shown to fill any pores in the joining specimens near the interlayer. Together with the demonstration of leak-tight joints between tube sections of reaction bonded and sintered $\mathrm{SiC}$ under the previous contract, these results provide the foundation for scale-up to joining of the larger and longer tubes needed for radiant burner and heat exchanger tube assemblies. The formation of $\mathrm{SiC}$ in situ is important because maintaining roundness of these large tubes is a technical challenge for the tube manufacturer, so that formation of a leak-tight joint may require some degree of gap filling. 


\subsection{PUBLICATIONS}

1. H. S. Sa'adaldin, W. M. Black, I. Ahmad, Y. L. Tian and R. Silberglitt, "Alternative Cavity Design for Microwave Joining of Long Ceramic Tubes," Mat. Res. Soc. Symp. Proc., Vol. 347, Materials Research Society, Pittsburgh, PA (1994), pp. 649-654.

2. T. H. A. Shan, R. Cozzens, Y. L. Tian and I. Ahmad, "Microwave Curing of Silicon Carbide Ceramics From a Polycarbosilane Precursor," Mat. Res. Soc. Symp. Proc., Vol. 347, Materials Research Society, Pittsburgh, PA (1994), pp. 729-734.

3. Y. L. Tian, W. M. Black, H. S. Sa'adaldin, I. Ahmad, and R. Silberglitt, "Dynamic Model for Electromagnetic Field and Heating Patterns in Loaded Cylindrical Cavities," Proceedings of the Symposium, Microwaves:Theory and Application in Materials Processing III, Ceramic Transactions, American Ceramic Society, Westerville, $\mathrm{OH}$ (in press).

4. I. Ahmad, R. Silberglitt, T. A. Shan, Y. L. Tian and R. Cozzens, "Microwave-Assisted Pyrolysis of SiC and Its Application to Joining," Proceedings of the Symposium, Microwaves: Theory and Application in Materials Processing III, Ceramic Transactions, American Ceramic Society, Westerville, $\mathrm{OH}$ (in press).

5. R. F. Cozzens, T. H. A. Shan, Y. L. Tian, I. Ahmad and R. Silberglitt, "Microwave Processing of Polycarbosilane and its Use as a Ceramic Joining Aid," Proceedings of the 30th IMPI Microwave Symposium, International Microwave Power Institute, Manassas, VA (1995). 


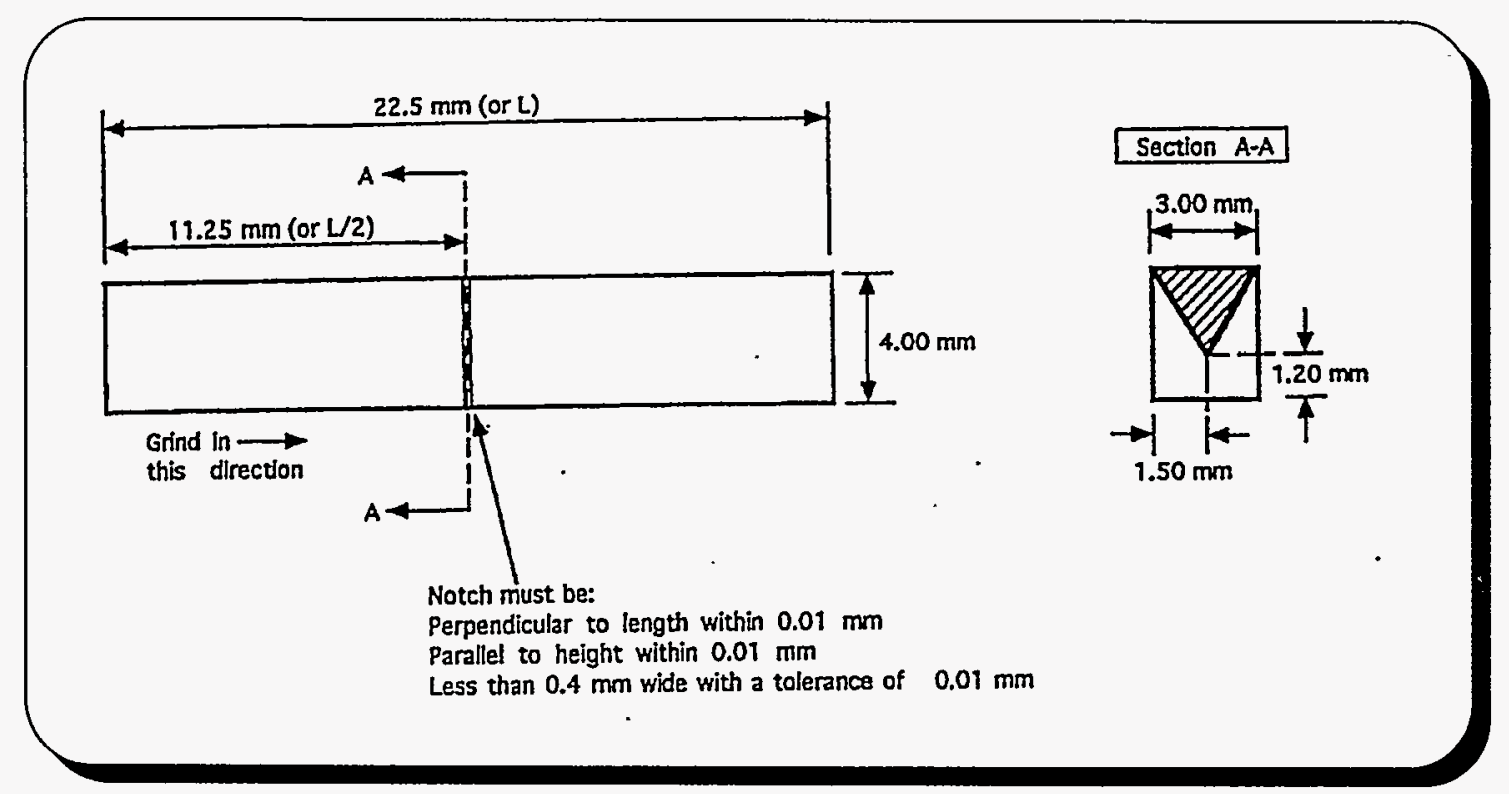

Figure 1: Schematic Illustration of Chevron Notched Fracture Toughness Specimen

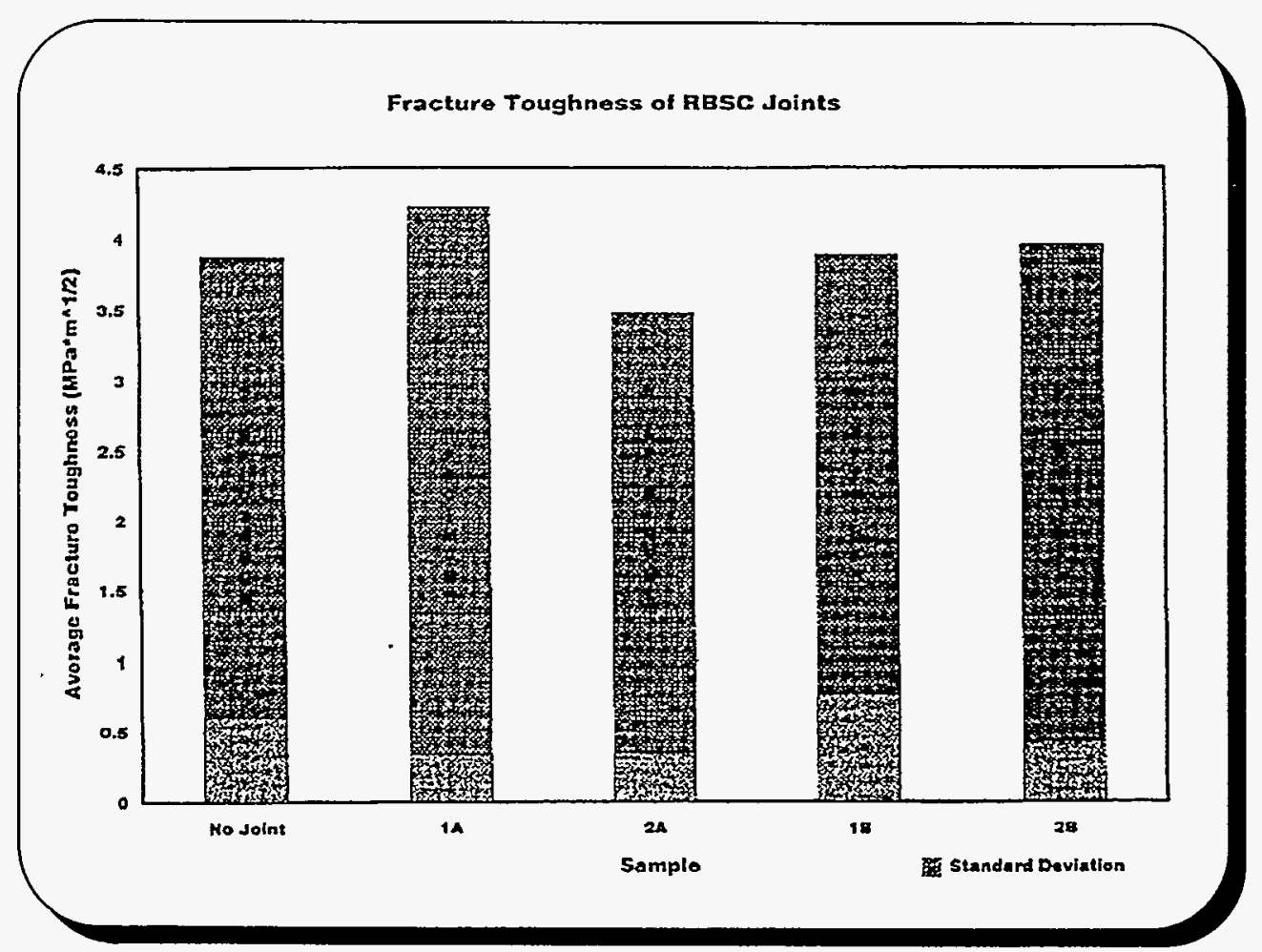

Figure 2: Fracture Toughness of RBSC Specimens (Joining Temperatures:

Specimen $1 \mathrm{~A}, 1465^{\circ} \mathrm{C}$; Specimen $2 \mathrm{~A}, 1565^{\circ} \mathrm{C}$; Specimen $1 \mathrm{~B}, 1515^{\circ} \mathrm{C}$; Specimen $2 \mathrm{~B}, 1420^{\circ} \mathrm{C}$ ) 


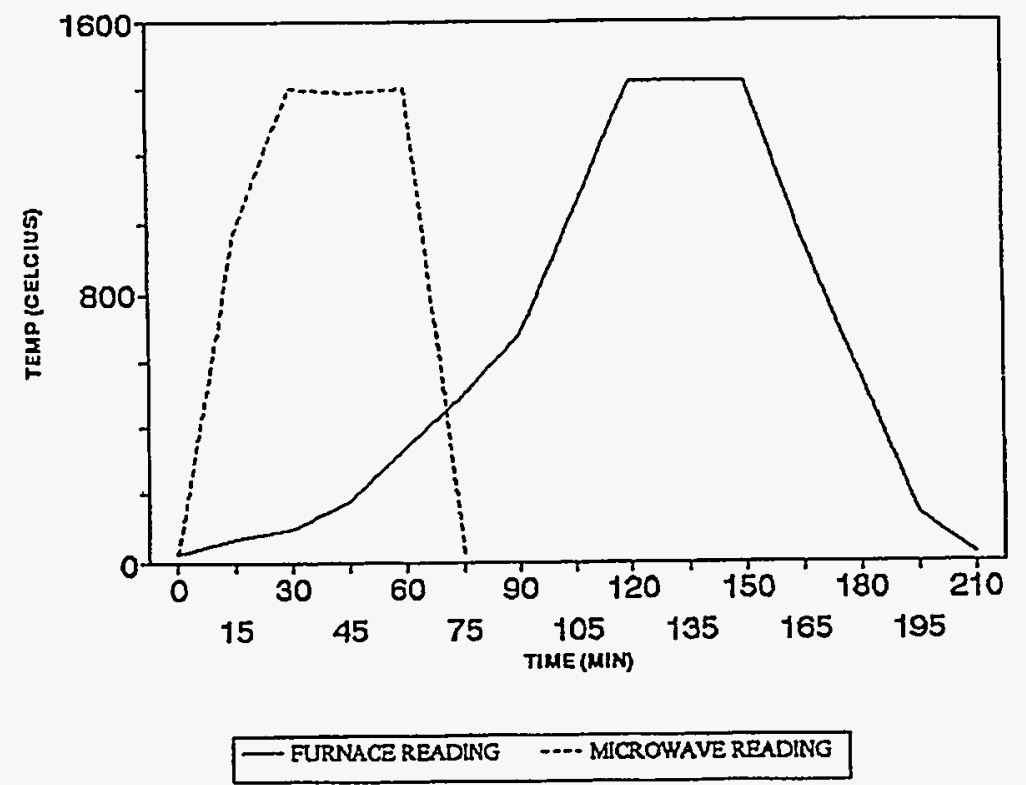

Figure 3: Comparison of Microwave and Conventional Heating Profiles for Pyrolysis of Polycarbosilane (PCS)

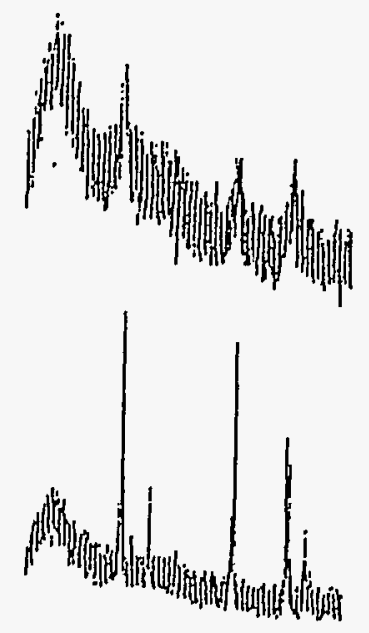

CONVENTIONAL $1400^{\circ} \mathrm{C}$

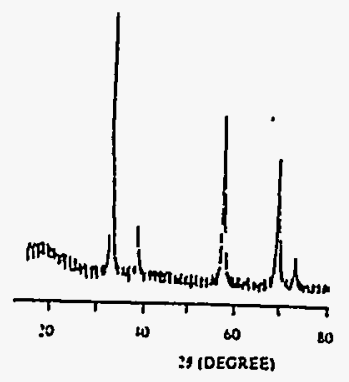

MICROWAVE $1400^{\circ} \mathrm{C}$

: COMMERCIAL SiC

Figure 4: Comparison of X-Ray Data for Product From Conventional and Microwave Curing of Polycarbosilane 


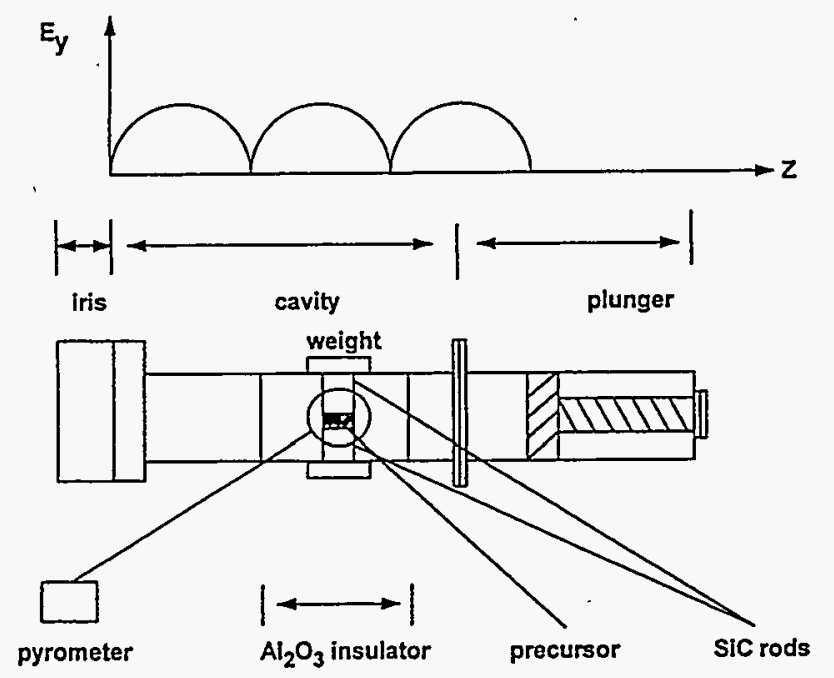

Figure 5: Experimental Setup for Microwave Joining Using Polycarbosilane Precursor

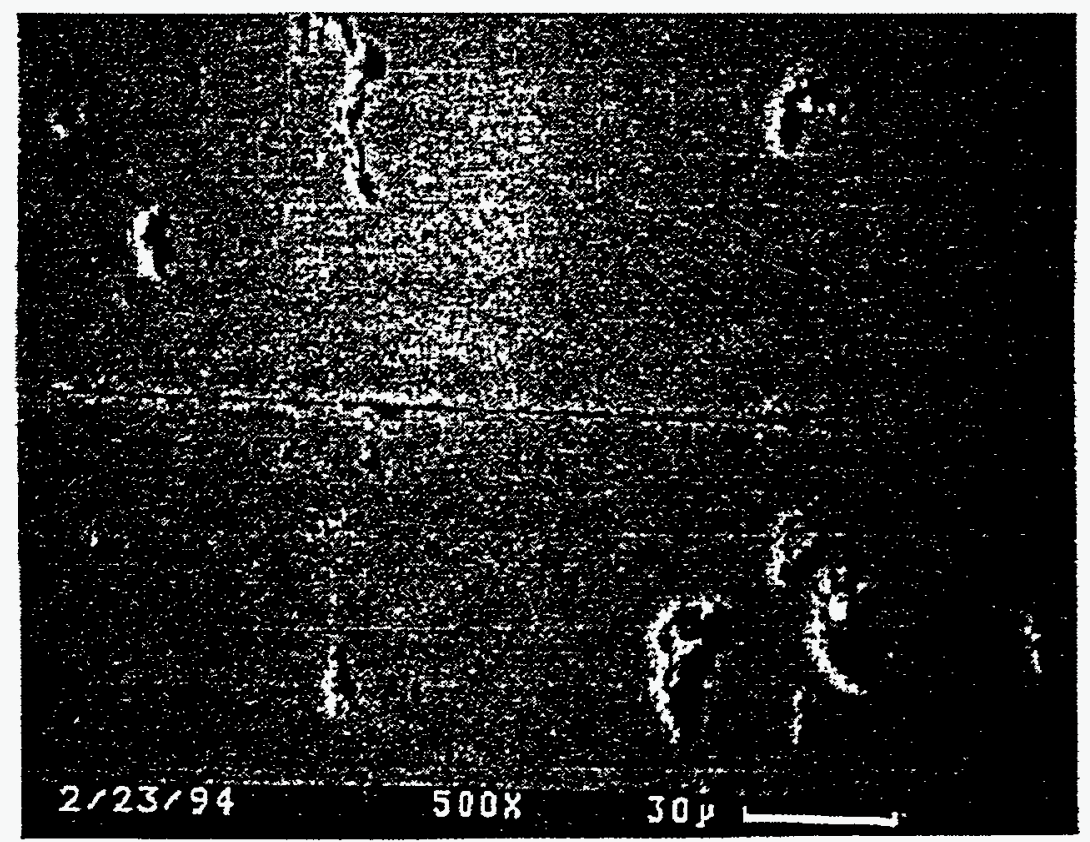

Figure 6: SEM Micrograph of Sectioned SiC Rods Joined Using Polycarbosilane Precursor 


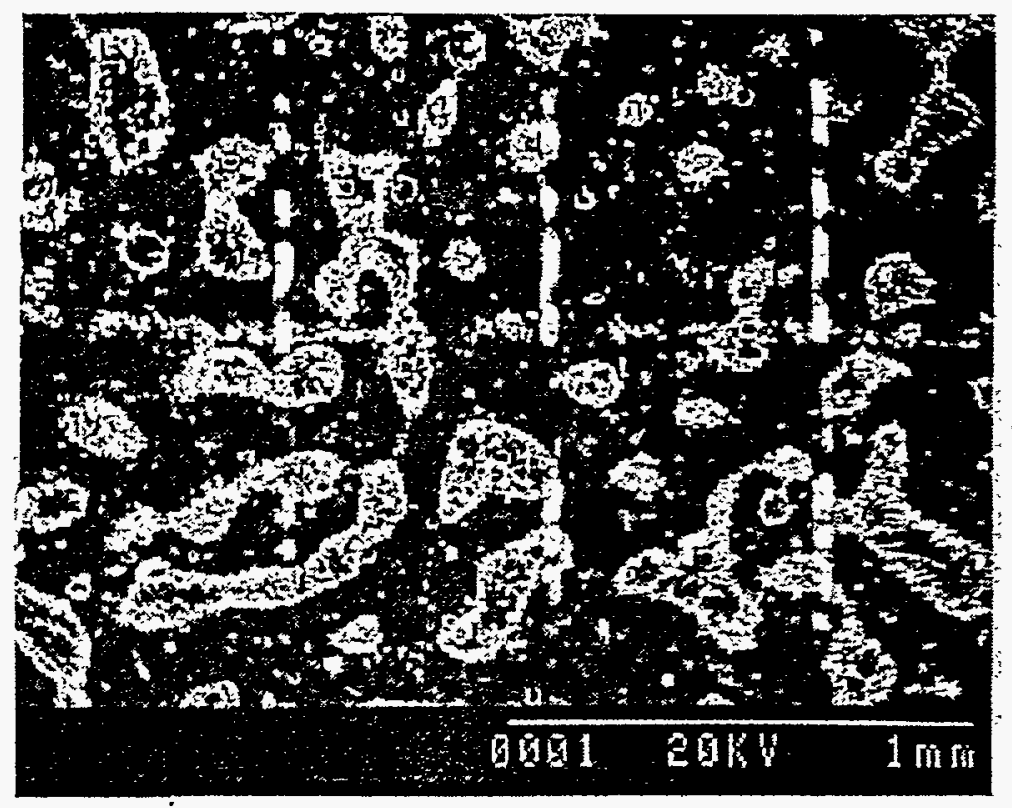

Figure 7: SEM of As-cut SiC Surface After Application of Polycarbosilane and Microwave Heating to $1400-1450^{\circ} \mathrm{C}$

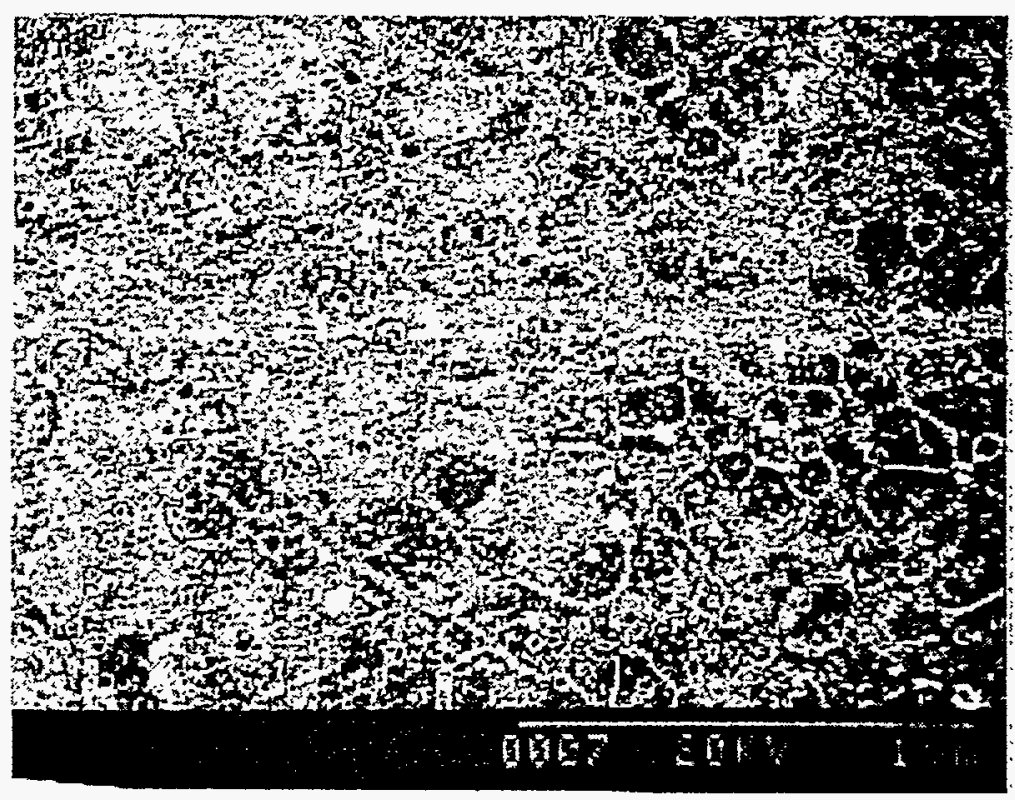

Figure 8: SEM of Ground and Etched SiC Surface After Application of Polycarbosilane and Microwave Heating to $1400-1450^{\circ} \mathrm{C}$ 


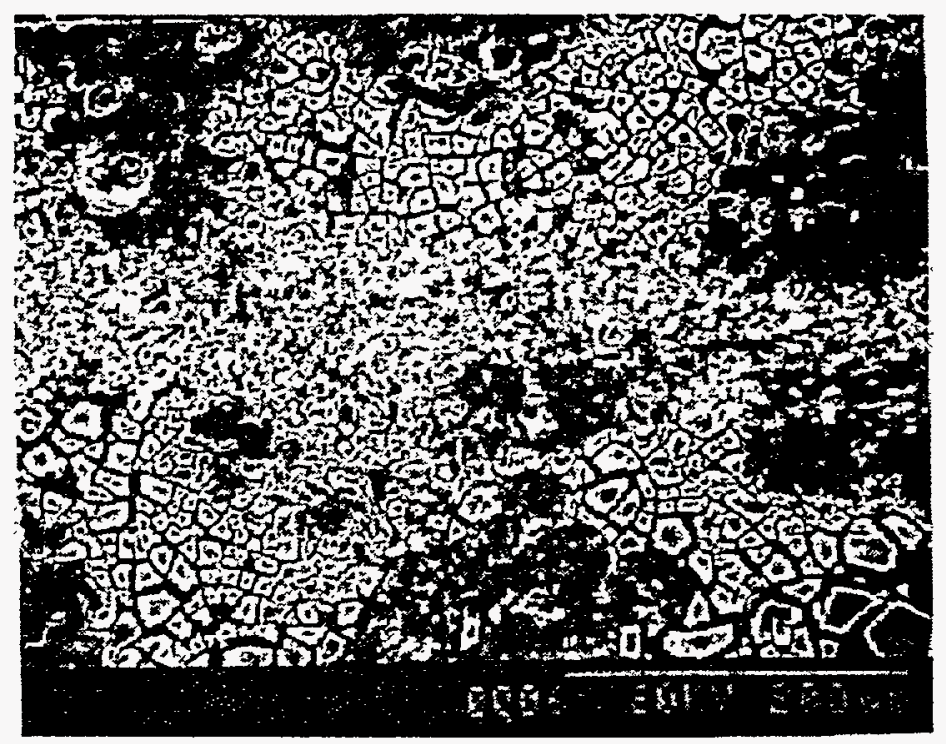

Figure 9: Higher Magnification of the SEM of Figure 8, Showing Adherence of SiC Formed From Decomposition of Polycarbosilane to the Ground and Etched Surface

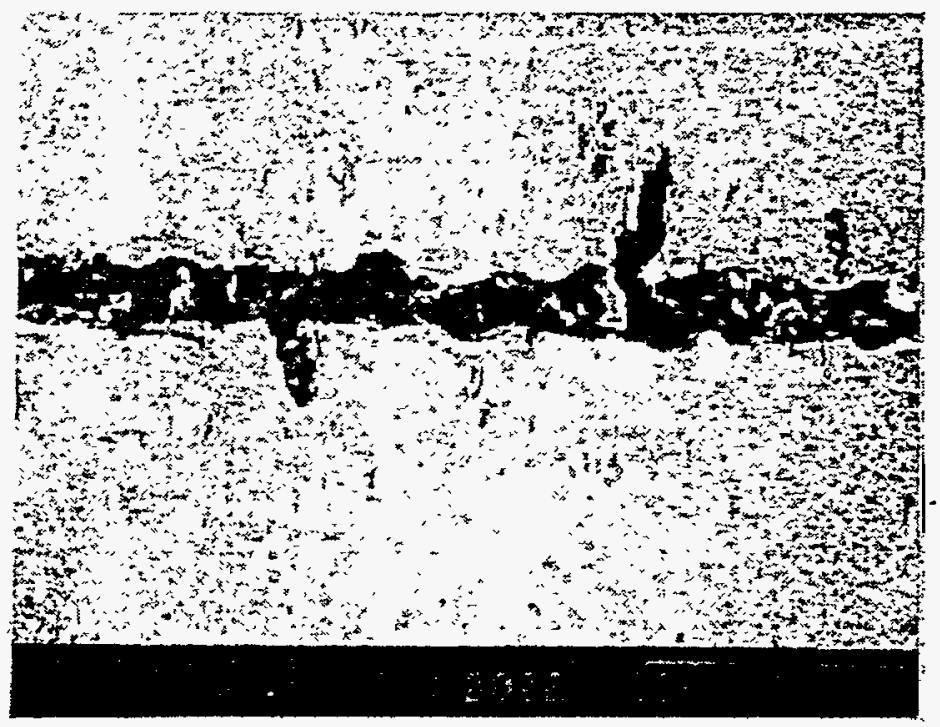

Figure 10: Cross-section of Sintered SiC Joined Using a Mixture of SiC and Polycarbosilane as the Interlayer Material 


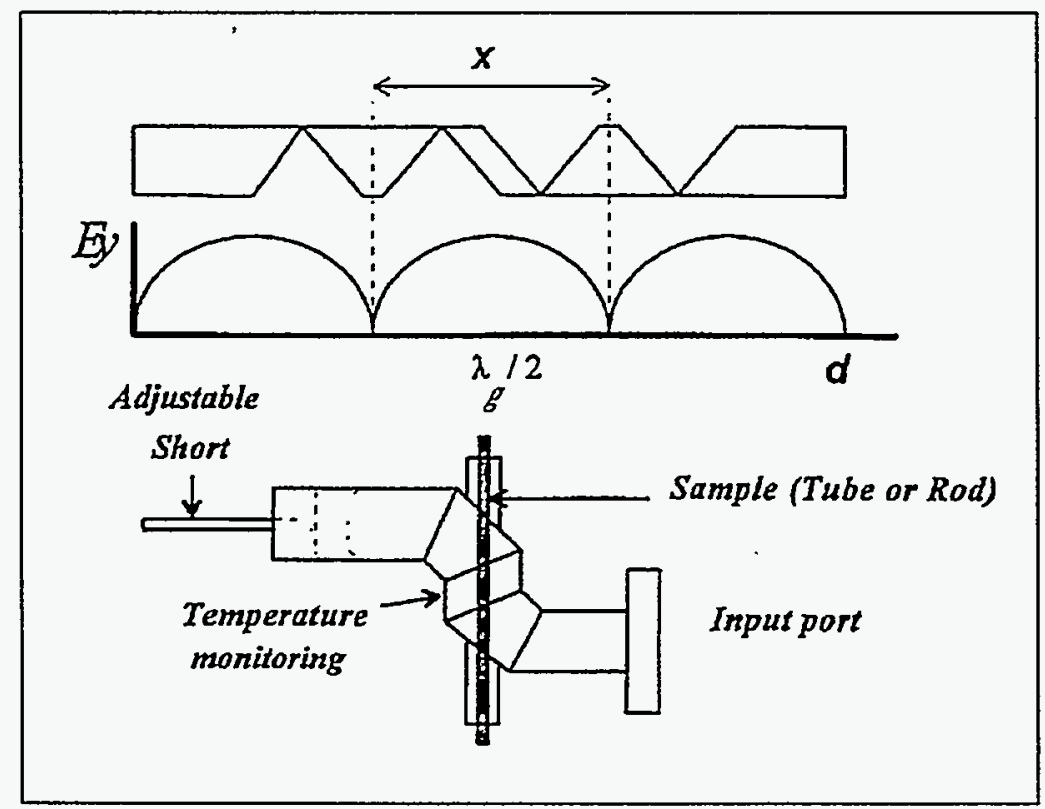

Figure 11: Schematic of Double Mitered Bend Cavity Showing Specimen Configuration

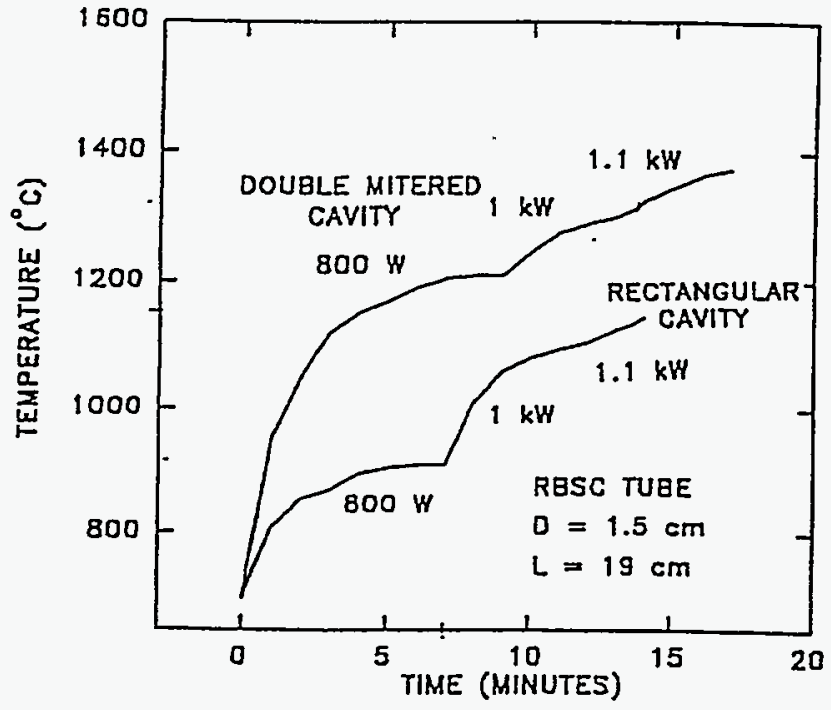

Figure 12: Comparison of Heating Profiles in Rectangular and Double Mitered Bend Cavities 


\title{
QUARTERLY TECHNICAL PROGRESS REPORT SUBCONTRACT NUMBER 4008E0014-3G RESEARCH ON MICROWAVE JOINING OF SiC FM TECHNOLOGIES, INC. JANUARY 1 - MARCH 31, 1995
}

\begin{abstract}
The objectives of this research project are to identify optimum time-temperature profiles for the microwave joining of silicon carbide and to develop new microwave joining methods that can be applied to accomplish in situ formation of silicon carbide interlayers and to join larger samples required for industrial applications:
\end{abstract}

\section{Summary of Work Performed}

Because of funding limitations, only a limited effort was performed during this contract period. The principal activity was continued investigation of the effect of specimen preparation on joining of $\mathrm{SiC}$ using polymer precursors to form $\mathrm{SiC}$ in situ at the interface. 


\title{
QUARTERLY TECHNICAL PROGRESS REPORT SUBCONTRACT NUMBER 4008E0014-3G RESEARCH ON MICROWAVE JOINING OF SiC FM TECHNOLOGIES, INC. APRIL 1 - JUNE 30, 1995
}

\begin{abstract}
The objectives of this research project are to identify optimum time-temperature profiles for the microwave joining of silicon carbide and to develop new microwave joining methods that can be applied to accomplish in situ formation of silicon carbide interlayers and to join larger samples required for industrial applications. Work during this reporting period was focused on investigation of the effect of specimen preparation on joining of $\mathrm{SiC}$ using polymer precursors to form $\mathrm{SiC}$ in situ at the interface. During this period, LANL also completed the evaluation of joints that were made by FMT using four different joining temperatures, as part of an effort to determine optimum joining temperature.
\end{abstract}

\section{Summary of Work Performed}

Task 1-Optimization of time-temperature profile

During a previous performance period, specimens of Coors reaction bonded silicon carbide (RBSC) tubes with outer diameter of $3.49 \mathrm{~cm}$ (1.375 in), inner diameter of $2.54 \mathrm{~cm}(1 \mathrm{in})$ and length of $2.54 \mathrm{~cm}(1 \mathrm{in})$ were joined at four different joining temperatures: $1420^{\circ} \mathrm{C}, 1465^{\circ} \mathrm{C}$, $1515^{\circ} \mathrm{C}$ and $1565^{\circ} \mathrm{C}$. In each case the joining temperature was maintained to within $15^{\circ} \mathrm{C}$ for approximately 30 minutes. The joined specimens were sent to Los Alamos National Laboratory for mechanical evaluation. Test bend bars were machined from each specimen and Chevron notches machined into the joint interface, as indicated in Figure 1. Figure 2 shows the fracture toughness determined from 4-point flexure tests of the notched test bend bars. The data labeled "no joint" were derived from test bend bars machined from an as-received specimen of RBSC. The average fracture toughness was determined from measurements on 6-8 specimens and the standard deviation is indicated by the shorter bars in Figure 2. The joining temperatures for each specimen were as follows: specimen $1 \mathrm{~A}$ at $1465^{\circ} \mathrm{C}$; specimen $1 \mathrm{~B}$ at $1515^{\circ} \mathrm{C}$; specimen $2 \mathrm{~A}$ at $1565^{\circ} \mathrm{C}$; specimen $2 \mathrm{~B}$ at $1420^{\circ} \mathrm{C}$. Figure 2 demonstrates that the optimum joining temperature is likely between $1420^{\circ} \mathrm{C}$ and $1500^{\circ} \mathrm{C}$, and perhaps very close to $1465^{\circ} \mathrm{C}$. Specimens joined near this optimum temperature have fracture toughness greater than the as received material. The standard deviation of the fracture toughness values for the joined specimens was also smaller than that for the as received material, except for specimen 1B, which had one data point with a fracture toughness value far different from all others. Inspection of the fracture surface of this test bar is being performed to see if its failure was caused by a defect in the material or by the specimen preparation process, rather than by failure of the joint. 


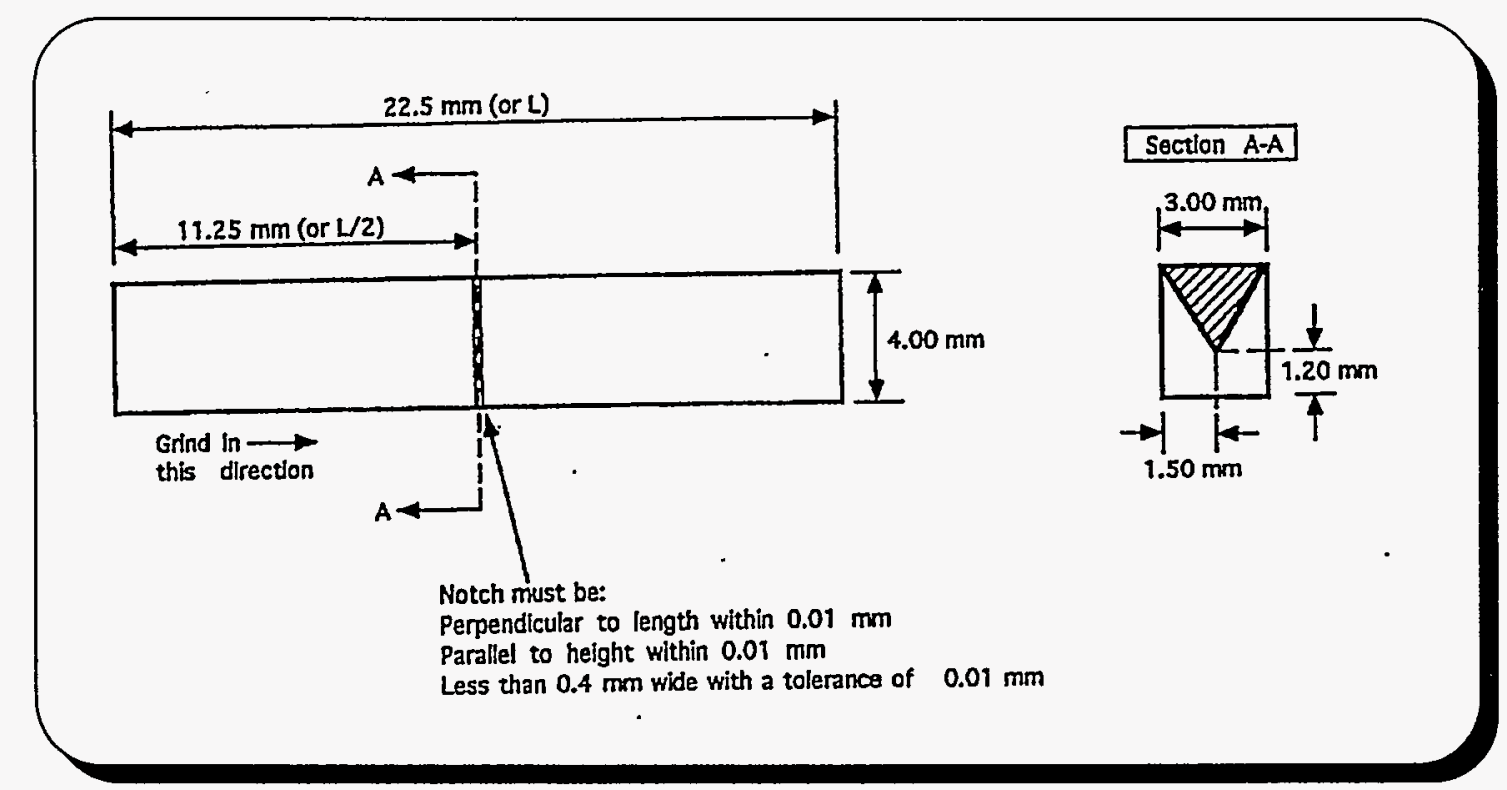

Figure 1: Schematic Illustration of Chevron Notched Fracture Toughness Specimen

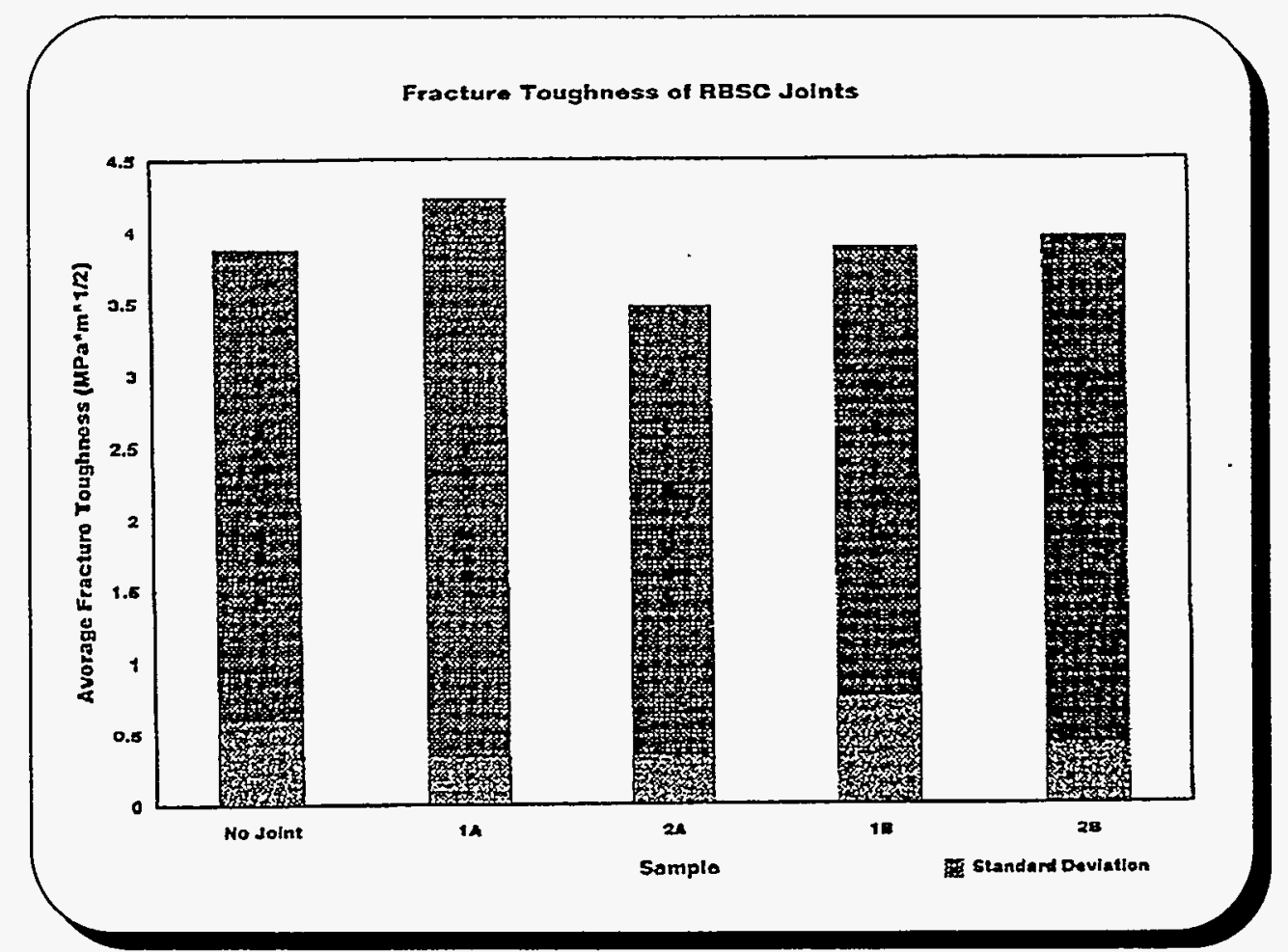

Figure 2: Fracture Toughness of RBSC Specimens (Joining Temperatures:

Specimen $1 \mathrm{~A}, 1465^{\circ} \mathrm{C}$; Specimen $2 \mathrm{~A}, 1565^{\circ} \mathrm{C}$; Specimen $1 \mathrm{~B}, 1515^{\circ} \mathrm{C}$; Specimen $2 \mathrm{~B}, 1420^{\circ} \mathrm{C}$ ) 
A detailed evaluation was performed of the effect of surface preparation on the joining of sintered $\mathrm{SiC}$, using microwave heating for the decomposition of polycarbosilane (PCS) to form $\mathrm{SiC}$ in situ at the interface. The specimens were Hexoloy ${ }^{\mathrm{TM}}$ sintered $\mathrm{SiC}$ rods $0.95 \mathrm{~cm}(0.375 \mathrm{in})$ in diameter and $0.5 \mathrm{~cm}(0.197 \mathrm{in})$ long, which were purchased from the Carborundum Company. Commercial PCS having a molecular weight of 1400 (manufactured by Nippon Carbon Corporation, Tokyo, Japan) was purchased from Dow Corning. Four sets of specimens were prepared using different surface treatments. All four sets of specimens were cut from as-received rods using a Buehler Low Speed Saw and a high concentration diamond blade. PCS was dissolved in hexane and applied to the surface to be joined. For the first set of specimens, the PCS solution was applied directly to the as-cut surface. For the second set, the surfaces to be joined were etched in $40 \%$ hydrofluoric acid before the PCS was applied. The joining surfaces of the other two sets of specimens were ground on a diamond wheel. One set of surfaces was then also etched before PCS application, while the other was not.

The specimens were placed in a $\mathrm{TE}_{103}$ single mode cavity applicator which had been modified under a previous task to allow processing under a mixed reducing atmosphere of $95 \%$ nitrogen and $5 \%$ hydrogen. Microwave power was coupled to the specimens using an adjustable iris and plunger and the specimens were heated to $1400-1450^{\circ} \mathrm{C}$ and held in this temperature range for 30 minutes. (Previous work has demonstrated that microwave heating of PCS to $1400^{\circ} \mathrm{C}$ provides a high degree of crystalline $\mathrm{SiC}$.) These specimens either did not join or were weakly bonded. However, investigation of the adherence of SiC formed from the PCS on the sintered $\mathrm{SiC}$ surface indicated that the ground and etched surface was most favorable for joining. An additional set of specimens was then prepared using grinding and etching of the surface. In addition, a mixture of SiC powder and PCS was applied to the surface to be joined. This set of specimens was heated using the same conditions as above, resulting in a good joint.

Figures 3 and 4 are Scanning Electron Micrographs (SEMs) of the surface of the specimens which had the PCS applied to the as-cut surface and to the ground and etched surface, respectively. Both surfaces were scratched with a sharp metal point under a load of 820 grams in order to investigate the adherence of the SiC formed from the decomposition of the PCS. Comparison of the SEMs shows greatly enhanced wetting and spreading of the $\mathrm{SiC}$ formed from the PCS on the ground and etched surface. SEMs (not shown) of surfaces that were either ground or etched also showed improvement over the as-cut surface, but the combination of grinding and etching provided the best wetting and spreading. Figure 5 is a higher magnification of the micrograph shown in Figure 4, which indicates that larger flakes of $\mathrm{SiC}$ were peeled off by the metal point, but good coverage of the scratched area remained, suggesting that the smaller flakes were adherent. Figure 6 is an SEM of a cross-section of the specimen joined using the mixture of SiC and PCS, after grinding and etching of the surfaces to be joined. A continuous joint interlayer approximately 50-60 $\mu \mathrm{m}$ in thickness was formed. In addition, a combination of the $\mathrm{SiC}$ introduced at the interlayer and the $\mathrm{SiC}$ formed from the PCS completely filled the pores near the interface of the joined specimens. 


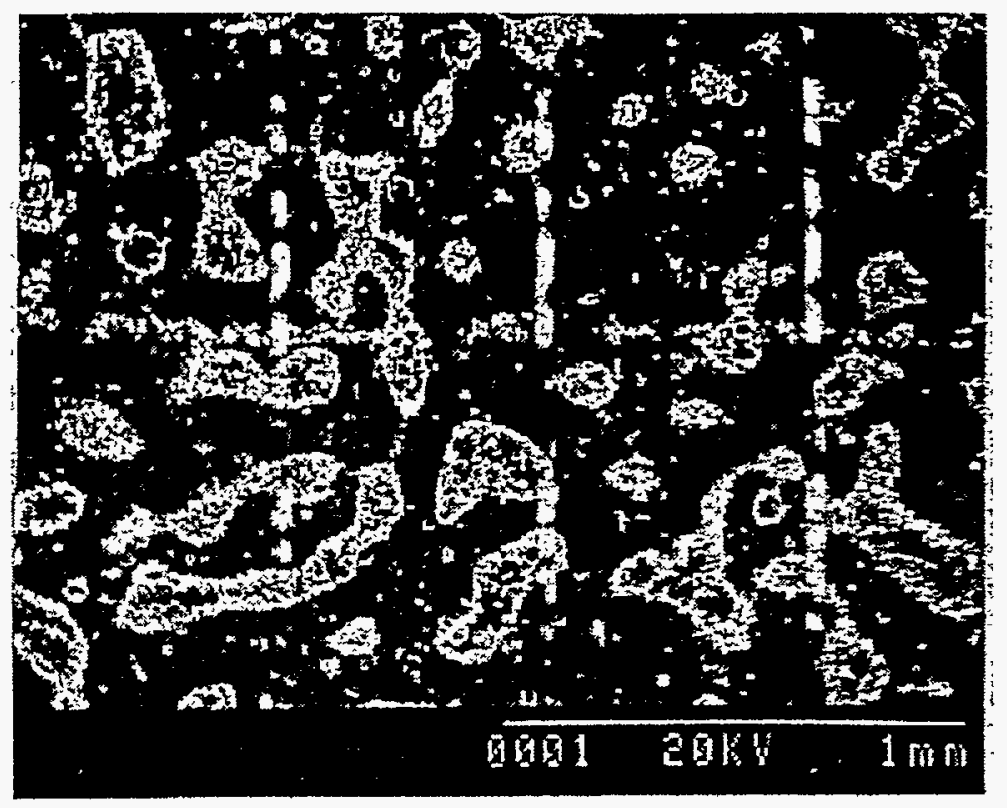

Figure 3: Scanning Electron Micrograph of As-cut SiC Surface After Application of Polycarbosilane and Microwave Heating to $1400-1450^{\circ} \mathrm{C}$

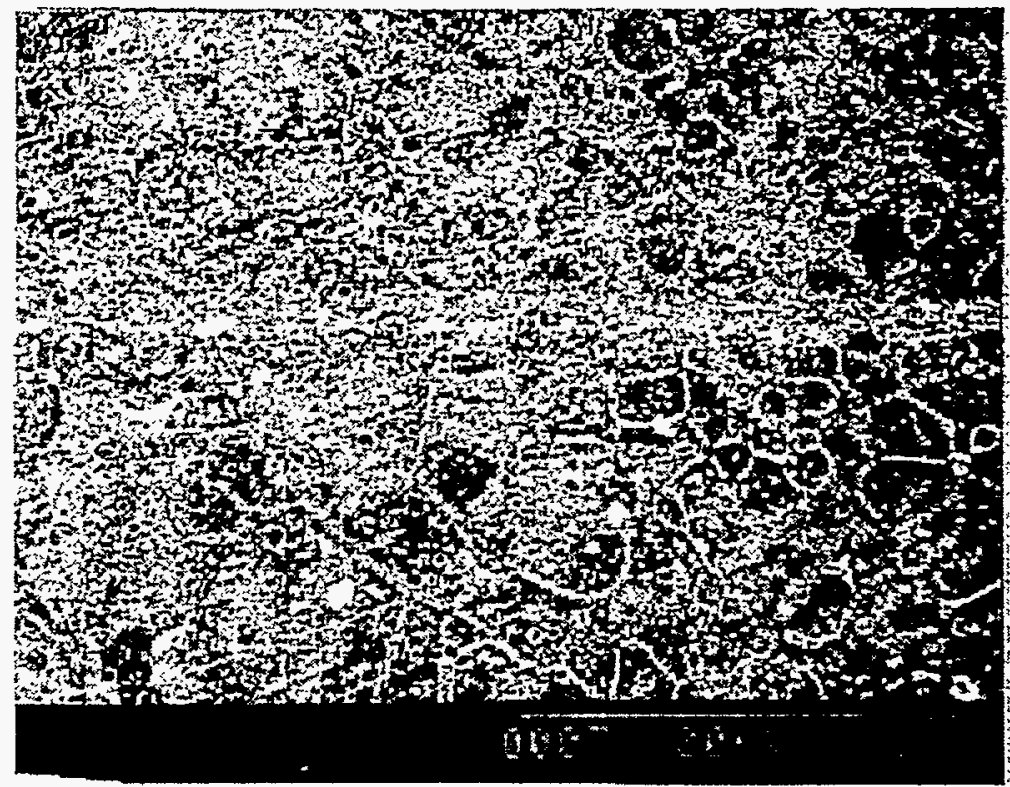

Figure 4: Scanning Electron Micrograph of Ground and Etched SiC Surface After Application of Polycarbosilane and Microwave Heating to $1400-1450^{\circ} \mathrm{C}$ 


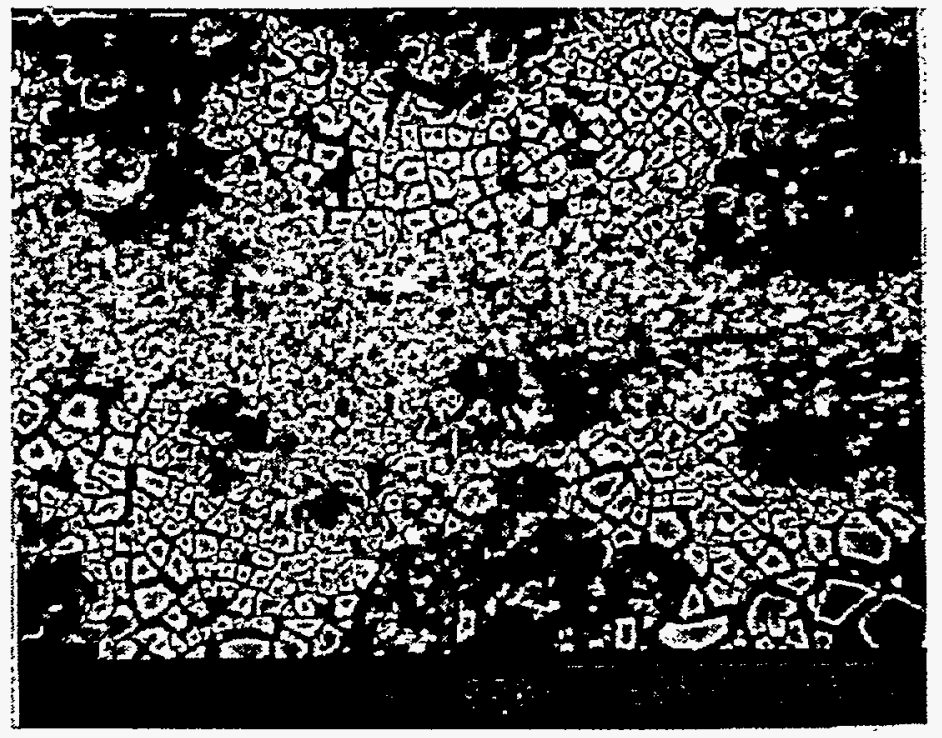

Figure 5: Higher Magnification of the SEM of Figure 4, Showing Adherence of SiC Formed From Decomposition of Polycarbosilane to the Ground and Etched SiC Surface

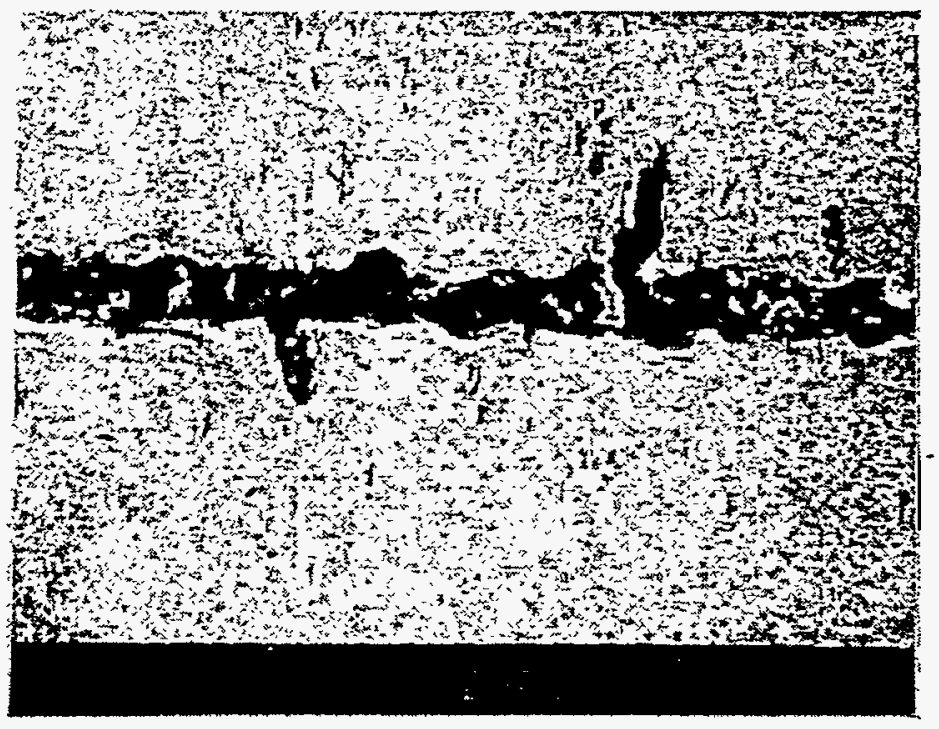

Figure 6: Cross-section of Sintered SiC Joined Using a Mixture of SiC and Polycarbosilane as the Interlayer Material 


\section{Presentations}

Dr. Iftikhar Ahmad presented a paper describing the work on joining of SiC using PCS at the American Ceramic Society (ACers) Symposium on Microwave Processing during the ACerS Annual Meeting and Exposition, April 30-May 4, 1995 in Cincinnati, OH. Dr. Richard Silberglitt made a presentation on the work performed under this contract at the Advanced Industrial Materials (AIM) Program Annual Meeting, June 14-16, 1995, in Washington, D.C.

\section{Publications}

Two papers resulting from this work have been submitted for publication in the proceedings of the ACerS Microwave Symposium, which is currently in press as a volume of

Ceramic Transactions. These papers are "Dynamic Model for Electromagnetic Field and Heating Patterns in Loaded Cylindrical Cavities," Y.L. Tian, W.M. Black, H.S. Sa'adaldin, I. Ahmad, and R. Silberglitt and "Microwave-Assisted Pyrolysis of SiC and Its Application to Joining," I. Ahmad, R. Silberglitt, T.A. Shan, Y.L. Tian, and R. Cozzens. 